\title{
ECONOMIA CRIATIVA NO ESTADO DE MINAS GERAIS
}

\section{CREATIVE ECONOMY IN THE STATE OF MINAS GERAIS}

\section{Suzana Quinet de Andrade Bastos ${ }^{1}$ Verônica Lazarini Cardoso ${ }^{2}$ Evelim Nascimento de Oliveira ${ }^{3}$}

\begin{abstract}
Resumo
O desenvolvimento de um país ou de uma região está cada dia mais dependente de inovações, tanto de tecnologias quanto de recursos renováveis e de ideias, porém esta última quando interligada à criatividade, a imaginação e a inovação abrem novas possibilidades de crescimento e desenvolvimento. Assim, o trabalho busca analisar qual a participação da economia criativa nos municípios do Estado de Minas Gerais. O trabalho utiliza dados da RAIS e o período de análise é o ano de 2012. Os resultados revelam que o estado de Minas Gerais possui 863.969 empregos criativos espalhados por 105.615 estabelecimentos, a grande maioria de pequeno porte. A maioria da força de trabalho possui graus de instrução até o Ensino Fundamental e Ensino Médio Completo. Dos 853 municípios que compõem o estado, os que se destacam possuindo atividades da cadeia criativa se localizam principalmente nas Regiões Metropolitana, Zona da Mata, Campo das Vertentes e Sul de Minas, estando as atividades principalmente concentradas na região da capital.
\end{abstract}

Palavras-chave: economia criativa, cidades criativas, atividades criativas, Minas Gerais.

\begin{abstract}
The development of a country or a region is increasingly dependent on innovations of both technologies and renewable resources and ideas, but the latter, when linked to creativity, imagination and innovation, opens new possibilities for growth and development. Thus, the work seeks to analyze the participation of the creative economy in the municipalities of the State of Minas Gerais. The work uses data from the RAIS and the analysis period is the year 2012. The results reveals that the state of Minas Gerais has 863,969 creative jobs spread across 105,615 establishments, the vast majority of them small. Most of the workforce has degrees of instruction through Elementary and High School Completion. Of the 853 municipalities that make up the state, the ones that stand out having activities of the creative chain are located mainly in the Metropolitan, Mata, Campo das Verentes and Sul de Minas Regions, with activities mainly concentrated in the region of the capital.
\end{abstract}

Keywords: creative economy, creative cities, creative activities, Minas Gerais.

\footnotetext{
${ }^{1}$ Doutora em Planejamento Urbano e Regional pela Universidade Federal do Rio de Janeiro (2004). Professora Associado 3 da Universidade Federal de Juiz de Fora, professora do Programa de Pós-Graduação em Economia Aplicada da UFJF e Bolsista de produtividade do CNPq. E-mail: quinet.bastos@ufjf.edu.br

2 Mestre em Economia Aplicada pelo Programa de Pós-Graduação em Economia Aplicada da Universidade Federal de Juiz de Fora (PPGEA/UFJF). E-mail: veronicalazarini@yahoo.com.br

${ }^{3}$ Graduada de Economia e Bolsista de Iniciação Cientifica. E-mail: enoecojf@gmail.com
}

Revista de Direito da Cidade, vol. 08, no 4. ISSN 2317-7721 pp. 1778 - 17991778 


\section{INTRODUÇÃO}

A criatividade está diretamente ligada ao conceito de novidade, capacidade de transformação, de reinventar, de buscar a solução de problemas e de união de ideias. Interpretando esse conceito em termos econômicos, a criatividade seria um insumo abundante, renovável e o mais importante é que o seu uso só faz aumentar o seu estoque, além do fato da concorrência entre os agentes criativos da economia atrair e estimular a atuação de novos produtores.

Com isso, a criatividade e principalmente a diversidade cultural no Brasil passa a ser compreendida muito além de um bem a ser valorizado, mas sim como uma espécie de ativo fundamental para uma nova compreensão do desenvolvimento econômico. A novidade reside no reconhecimento de que a criatividade tem o papel de motivar novos modelos de negócios, processos organizacionais e uma arquitetura institucional que galvaniza setores e agentes econômicos e sociais.

Com a ampliação dos conceitos de criatividade, a cultura deixou de ser vista apenas e exclusivamente como um meio de desenvolvimento social e a partir da Conferência Ministerial da UNCTAD XI, em 2004, o tema das indústrias criativas passou a ser discutido e integrado na agenda de desenvolvimento internacional (PINTO, ARAÚJO, 2013).

Não existe uma definição exata do que seja Indústria Criativa, segundo Reis (2008):

Caves, por exemplo, entende por indústrias criativas as relacionadas a artes, cultura e entretenimento em geral. Já para Howkins, o divisor de águas da Economia Criativa seria o potencial de gerar direitos de propriedade intelectual (a "moeda" da Economia Criativa), expandindo sua abrangência dos direitos autorais para desenhos industriais, marcas registradas e patentes. (...) Já John Hartley propõe uma definição plural: a ideia de indústrias criativas busca descrever a convergência conceitual e prática das artes criativas (talento individual) com indústrias culturais (escala de massa) no contexto das novas tecnologias de mídia (TICs) em uma nova economia do conhecimento, para o uso dos novos consumidores-cidadãos interativos (REIS, 2008, p.22-23).

A maioria das pesquisas na área se baseia no conceito mais completo e na definição da ONU sobe a chancela da UNCTAD que define indústrias criativas como "ciclos de criação, produção e distribuição de bens e serviços que usam a criatividade e capital intelectual como insumos primários" (FIRJAN, 2008, p.14). A partir do conceito de indústria criativa outros termos foram 
cunhados como economia criativa, cidade criativa e classe criativa, em que se envolvia a busca da importância da criatividade na trajetória econômica e desenvolvimentista de uma região e seus impactos nos demais setores da economia (MEDEIRO JUNIOR, et al. 2011). Essas novas denominações foram consequência, segundo Machado (2011), da tentativa de desvincular o estigma criado em relação à mercantilização da cultura e ao assalariamento dos artistas que criava uma conotação negativa ao papel das indústrias culturais nos países desenvolvidos.

Em 2004, através do encontro quadrienal da Unctad em São Paulo se iniciou a discussão de economia criativa no Brasil. Já em 2005, com o apoio do Ministro Gilberto Gil e o Embaixador da Unctad organizou-se o Fórum Internacional de Indústrias Criativas, que aconteceu em Salvador, e a partir desse acontecimento, seguiu-se o debate sobre a economia criativa no país.

Segundo o Ministério da Cultura (BRASIL, 2011, p.23) a Economia Criativa compreende as "dinâmicas culturais, sociais e econômicas construídas a partir do ciclo de criação, produção, distribuição/difusão e consumo/fruição de bens e serviços caracterizados pela prevalência de sua dimensão simbólica". Porém trata-se de um conceito novo e em construção, mesmo nos países desenvolvidos, devido principalmente à necessidade de adequá-lo às especificidades e características sociais, culturais, políticas, e econômicas dos diferentes países em que está inserido.

Para a Secretaria da Economia Criativa,

(...) setores criativos são aqueles cujas atividades produtivas têm como processo principal o ato criativo gerador de um produto, bem ou serviço, cuja dimensão simbólica é determinante do seu valor, resultando em produção de riqueza cultural, econômica e social (BRASIL, 2011, p. 12).

Segundo Carvalho (2011), a economia criativa tem o poder de transformar, de mudar, de dividir, de repartir e de incluir. Ou seja, o investimento no setor levaria ao alcance de uma maior homogeneização social, e transformação de realidades desiguais. Para Reis (2008) a economia criativa valoriza a singularidade, o simbólico e aquilo que é intangível, a criatividade, sendo esses seus três pilares.

Segundo Coutinho (2011), no século XXI se reconhece que quanto mais denso, diverso e rico o conteúdo cultural de uma sociedade, maiores as suas possibilidades de desenvolvimento.

(...) especialmente nos países mais pobres, a economia criativa é uma fonte de criação de empregos, oferecendo oportunidades para a mitigação da pobreza. Atividades criativas, especialmente as ligadas às artes e às festas culturais tradicionais, geralmente levam à inclusão das minorias, mantidas à distância. Isso facilita a maior absorção de parcelas de jovens talentos

Revista de Direito da Cidade, vol. 08, № 4. ISSN 2317-7721 pp. 1778 - 17991780 
marginalizados que, na maioria dos casos, envolvem-se com atividades criativas no setor informal da economia (DUISENBERG, 2008, p. 61).

A identificação desse setor e de todo seu potencial econômico nos municípios, segundo Reis (2011), envolve a articulação de um pacto social, econômico e político entre os setores público, privado, a sociedade civil, a academia e as organizações multilaterais. Apesar de a criatividade ser um recurso importante não é suficiente para o alcance do sucesso, por isso há uma necessidade de provimento de uma boa gestão. Por isso, pouco adianta falar de economia criativa e do reconhecimento do potencial econômico da cultura, se um passo ainda mais fundamental não tiver sido dado antes o desenho de uma política pública clara, com base no contexto local.

Com isso, segundo Reis (2008), torna-se importante definir não como medir, mas sim o que medir e encontrar as características da economia criativa adequadas a cada região, identificando quais são os serviços desenvolvidos, empregos, oportunidades de renda, potencial de crescimento, a competitividade, sua concentração, o nível de educação e instrução do capital humano, a forma espacial (ocupação territorial), em fim, o verdadeiro potencial existente no setor e definir qual a melhor ação para transformá-lo em um verdadeiro motor de desenvolvimento econômico para as regiões.

Assim, levantar dados e informações sobre a Economia Criativa no Brasil, com o intuito de articular e estimular os empreendimentos em educação, infraestrutura e na criação de marcos legais para que tal provável fonte de desenvolvimento econômico regional seja difundida, estimulada e apoiada no país é fundamental para o desenvolvimento do setor. (BRASIL, 2011)

O Brasil é um país rico em diversidades culturais, e acredita-se que cada região é composta de um grande potencial econômico intrínseco em sua cultura. São grandes a gama de produtos e serviços produzidos no país, tornando maiores os desafios para que a economia criativa seja assumida como política desenvolvimentista, devido principalmente à necessidade de pensar e identificar produtos que se restrinjam a cada determinada área ou segmento criativo, porém, cada localidade, cidade, ou território apresentam suas especificidades de produção e cultura, e tendem a concentrar grande parte do potencial produtivo da economia criativa.

O início dos interesses no Brasil, pelo conhecimento do potencial econômico que o setor poderia revelar, é visto já em 2003, onde o Sistema de Informações e Indicadores Culturais (SIIG/IBGE) mostrava que, o número de trabalhadores registrados na área da cultura era de 1,055 milhão de pessoas, correspondendo a 5,7\% dos empregos formais do país, que os gastos da 
população brasileira com cultura ocupavam o 4 ㅇ lugar das despesas das famílias, atrás apenas da alimentação, habitação e transporte, e que o peso da cultura na oferta de empregos por setor econômico era de 55,3\% nos serviços; 25,6\% na indústria e 19\% no comércio (MACHADO, 2011).

Para Barreto (2008), em 2008, no Brasil, o setor era responsável por 8\% do PIB e em 2009 por 4,5\%_da mão de obra formalizada no país. Já em 2012, verificou-se que o Brasil possuía 791.809 estabelecimentos ligados à economia criativa, ou seja, estabelecimentos que produzem e empregam produtos e mão de obra da cadeia, número este que representa $21,4 \%$ dos do total de estabelecimentos no país.

Dentre os principais estados economicamente significativos no país, o Estado de Minas Gerais é o maior em número de municípios com 854 no total, o segundo em população e o $3^{\circ}$ mais rico do Brasil, com um PIB de aproximadamente R\$351 bilhões (em 2010), atrás apenas do Rio de Janeiro (R\$407 bilhões) e São Paulo (R\$1,4 trilhão) - IBGE/2012, e devido principalmente a todo seu potencial econômico e territorial/populacional, é indispensável em termos de política econômica investigar as prováveis potencialidades econômicas das cadeias criativas existentes no estado e o seu papel no desenvolvimento social e econômico.

O objetivo deste trabalho é identificar as cidades e territórios criativos no Estado de Minas Gerais, de forma a verificar quais são os setores da economia criativa existentes nos municípios mineiros, bem como a representatividade destes setores na geração de emprego na região. Para este fim utilizam-se dados extraídos da RAIS (Relação Anual de Informações Sociais) para o ano de 2012.

Além desta introdução o trabalho é composto por mais quatro sessões: revisão de literatura, metodologia e base de dados, análise dos resultados e considerações finais.

\section{CIDADE CRIATIVA}

Uma cidade criativa é um sistema social, cultural e econômico de natureza urbana, no qual a criação de oportunidades, prosperidade e riqueza está baseada na habilidade de gerar valor com a força de ideias, informação, conhecimento e talento. (PARDO, 2011).

Assim como o conceito de economia criativa, cidade criativa busca enfatizar a importância que o processo criativo possui na trajetória de desenvolvimento econômico e de revitalização das cidades. (MEDEIRO JUNIOR, et al. 2011)

Revista de Direito da Cidade, vol. 08, № 4. ISSN 2317-7721 pp. 1778 - 17991782 
Segundo Reis (2009):

(...) o conceito de cidade criativa para alguns revela a efervescência do que é produzido criativamente no espaço urbano e seu potencial econômico. Para outros, o enfoque da produção se translada à prevalência de um ambiente capaz de gerar, capacitar, atrair e reter talentos que sustentem essa criatividade e seu valor econômico agregado. Uma terceira corrente constata a essência da cidade criativa na confluência entre capacidade de geração tecnológica, formação de uma mentalidade aberta e tolerante e atração de talentos (REIS, 2009, p. 206).

Para o autor (2009, p. 3), "cidade criativa pode ser entendida como uma cidade capaz de transformar continuamente sua estrutura socioeconômica, com base na criatividade de seus habitantes e em uma aliança entre suas singularidades culturais e suas vocações econômicas".

Segundo Carvalho (2011) aquela cidade que é capaz de transformar o seu contexto socioeconômico com base na valorização da cultura local, das particularidades que fazem a diferença de cada um e de cada parte, tem o potencial para se torna uma cidade criativa. Semelhantemente, para Lerner (2011) a identificação da capacidade e do potencial embutido tanto na população quanto na história de cada cidade torna possível que, mesmo aquela cidade que não seja criativa pode vir a se tonar uma.

A cidade criativa é aquela capaz de surpreender, de atiçar a curiosidade, o questionamento, o pensamento alternativo e, com isso, buscar soluções dentro de seu próprio potencial, assim segundo Reis e Urani (2011), independentemente do tamanho, da localização, da história, ou da condição socioeconômica, em uma cidade criativa deve-se sempre prevalecer três elementos característicos, sendo eles inovações tecnológicas, sociais, ambientais e culturais, como meio de solução de problemas ou antecipação de oportunidades.

O conceito de cidade criativa como lócus da economia criativa engloba além dos enfoques culturais, sociais e criativos, enfoques espaciais e territoriais fomentando a ideia de que as atividades criativas em sua grade medida são urbanas, visto que requer a proximidade com seus produtores e consumidores bem como com a mão de obra (MACHADO, 2011).

Para Strickland (2011):

A cidade criativa representa a Cidade do Futuro, tanto em forma, quanto em substância. Ela se beneficia da sua importância histórica como ponto focal, geográfico e econômico, une grupos, afeta economias de escala de suprimentos, informações, troca de ideias, concentrações de capital, proximidade de empregos e oportunidades de trabalho (STRICKLAND, 2011, p. 51).

Revista de Direito da Cidade, vol. 08, № 4. ISSN 2317-7721 pp. 1778 - 17991783 
Carvalho (2011) acredita que conectando atores sociais, como governos, empreendedores e empresários, instituições, escolas e universidades é possível desenvolver uma estrutura que pode ser chamada, "ganha-ganha", onde o capital de conhecimento é alavancado, trazendo benefícios para todos. Assim, a participação conjunta serviria para estimular os talentos, a diversidade e dar condições para que se agregue valor econômico e se dê vazão à geração de negócios.

A forma como as pessoas vão se interagir, se envolver e dinamizar a maneira de expor a sua criatividade juntamente com seus valores históricos, culturais, sociais e econômicos vai variar de acordo com cada região e dependerá de quem vive, quem trabalha, quem constrói ou construiu e/ou que se comunica com estes espaços geográficos.

Segundo Machado (2011) as vantagens de uma cidade podem ser uma combinação de duas ou mais condições, tais como: expressiva presença de classe criativa, dotação de equipamentos culturais, tradição em manifestações populares, renda média elevada, alta escolaridade média, presença de centros universitários, histórico de políticas de incentivo à cultura e ambiente de elevada "autoestima social" e "mente aberta" às inovações e aos diferentes grupos demográficos.

Contudo, apesar da participação histórica, cultural, humana e criativa, para que se possa explorar e ramificar essa economia, é necessário um planejamento urbano voltado para a promoção dessa cidade criativa e principalmente para as pessoas que ali vivem, com ações que construam uma estrutura de gestão socioeconômica, produtiva e ambiental do território e que ao mesmo tempo identifique os projetos e polos produtivos mais representativos na cidade.

As cidades, nesse sentido, e a partir daí, podem também competir para atrair, manter ou aumentar a sua classe criativa, através de redes de interações que se estabelecem entre os agentes produtivos que se relacionam, cooperam e confiam uns nos outros, construção e estabelecimento de um potencial científico e de realização de pesquisas, além de prover possibilidades de realização de investimentos de risco, e as aglomerações de produtores (MEDEIRO JUNIOR et al., 2011).

As perspectivas de crescimento econômico e desenvolvimento de cidades criativas vão demandar cada vez mais planejamentos públicos e privados e a união da classe envolvida para dinamizar o setor e fazer com que haja comprometimento do orçamento público, de infraestrutura básica e assim de iniciativas que darão impulso para a criação e desenvolvimento de potenciais polos criativos nos centros urbanos.

Revista de Direito da Cidade, vol. 08, no 4. ISSN 2317-7721 pp. 1778 - 17991784 


\section{Trabalhos Empíricos}

Júnior, Grand Júnior e Figueiredo (2011) analisaram a importância da economia criativa no desenvolvimento econômico na cidade do Rio de Janeiro investigando de qual forma esse setor se transforma em um motor do desenvolvimento econômico. Os autores utilizaram dados da Relação Anual de Informações Sociais (RAIS) do Ministério do Trabalho e Emprego e o estudo da FIRJAN (2008) para definição das atividades integrantes da economia criativa, reconhecendo três grandes áreas da cadeia da indústria criativa: o núcleo, as áreas relacionadas e as atividades de apoio indireto. Além disso, compararam as informações locais com as do estado do Rio de Janeiro, e analisaram o padrão espacial na cidade, de modo a relacioná-la com o desenvolvimento urbano. Concluíram que a economia criativa possui um importante papel no desenvolvimento econômico da cidade, sendo o segmento responsável por $11 \%$ do total dos empregos e $10 \%$ da massa salarial total. Já no âmbito espacial, a distribuição dos empregos da economia criativa é bastante concentrada na capital, respondendo por $76 \%$ do total de postos de trabalho das atividades integrantes do núcleo e 56\% das atividades relacionadas.

Machado (2011) definiu o perfil das cidades criativas no Brasil através da construção de tipologias, além de analisar perfil das classes criativas e medir a participação do consumo cultural efetuado pela população mais rica. Através dos dados da Munic/IBGE obteve cinco perfis de municípios: misto, nada criativo, pouco criativo, algo criativo e criativo e suas distribuições nas grandes regiões brasileiras. A PNAD/IBGE através da lista de ocupações da Classificação Brasileira de Ocupações (CBO - 2002) permitiu a análise do mercado de trabalho na economia criativa, do grau de formalidade e informalidade e da remuneração. A POF/IBGE permitiu o estudo do perfil de consumo dos bens e serviços culturais. Os principais resultados foram que as regiões Sul e Sudeste absorvem a maior fração de municípios criativos $(30,25 \%, 45,13 \%)$ e na região Nordeste está a maioria dos municípios não criativos (43,63\%). Em relação ao perfil da classe criativa, verificou-se que $2 \%$ da PEA nas regiões metropolitanas brasileiras estão envolvidas em atividades criativas, sendo a maioria no Rio de Janeiro e São Paulo, e que essas atividades apresentam alto grau de informalidade nas relações de trabalho, porém a redução desse grau de informalidade se dá de 2005 para 2008. A comparação do perfil dos que consomem e não consomem bens e serviços culturais, com relação ao dispêndio privado mostrou que o dispêndio das famílias com bens ainda é

Revista de Direito da Cidade, vol. 08, no 4. ISSN 2317-7721 pp. 1778 - 17991785 
baixo, contudo as áreas metropolitanas que apresentam esse gasto são geralmente de famílias chefiadas por mulheres e de pessoas mais novas (relação inversa entre idade e gasto), uma relação que não era esperada para os mais ricos.

Caiado (2011) objetivou definir as atividades pertencentes à Economia Criativa na cidade de São Paulo. Os dados utilizados foram a Relação Anual de Informações Sociais (RAIS) do Ministério do Trabalho e Emprego para definição das atividades da economia criativa e a PNAD/IBGE com a finalidade de extrair o número de atividades criativas no setor informal. Os principais resultados foram que o peso dos setores criativos no município de São Paulo é superior ao que se verifica no Estado de São Paulo e no Brasil. As empresas do setor no ano de 2009 empregavam cerca de 140 mil trabalhadores formais, o que corresponde a $3 \%$ de todo o emprego formal na cidade. Os vínculos empregatícios nos setores criativos entre 2006 e 2009 apresentou um aumento de 648 mil para 753 mil, o que equivale, a uma variação de 16,1\%. O município de São Paulo alcança a quarta posição, com quase 141 mil empregos vinculados a atividades criativas, equivalendo a 3,04\% em termos relativos. A taxa de formalização da economia criativa é superior à do total da economia com diferença de 3,5 pontos. A participação da Economia Criativa é bastante superior à da economia como um todo, o que mostra uma especialização da cidade de São Paulo nestes setores.

Pinto e Araújo (2013) utilizando metodologia desenvolvida por Firjan $(2008,2012)$ para o Mapeamento das Indústrias Criativas no Brasil, classificam as atividades econômicas e ocupacionais com base nos dados da RAIS disponibilizado pelo Ministério do Trabalho e Emprego para investigar a participação das indústrias criativas nos empregos e na renda dos brasileiros. Foi utilizada a Classificação Nacional de Atividades Econômicas (CNAE) na definição das atividades pertencentes à indústria criativa juntamente com os dados da Classificação Nacional de Ocupações (CBO) para informações referentes à força de trabalho. Como principais resultados têm-se: do total de trabalhadores brasileiros, 1,7\% (810mil) pertencem ao mercado formal do núcleo criativo. Em relação à remuneração, enquanto o rendimento mensal médio do trabalhador brasileiro era de R\$ 1.733 em 2011, o dos profissionais criativos chegou a $R \$ 4.693$, quase três vezes superior ao patamar nacional sendo o segmento de P\&D o que apresentava o maior salário médio. Na análise dos estados $2,3 \%$ e 2,2\% do mercado de trabalho de São Paulo e Rio de Janeiro respectivamente, são representados por profissionais que têm como principal ferramenta de trabalho a criatividade.

Revista de Direito da Cidade, vol. 08, no 4. ISSN 2317-7721 pp. 1778 - 17991786 
No Nordeste, o destaque é o estado do Ceará, em que o segmento de Moda é responsável por $13,1 \%$ do núcleo criativo estadual, percentual mais de duas vezes superior ao patamar nacional $(5,4 \%)$.

\section{METODOLOGIA E BASE DE DADOS}

O trabalho utiliza dados da RAIS, classificados pela Classificação Nacional de Atividades Econômicas (CNAE 2.0) para o ano de 2012. A RAIS foi desenvolvida pela Receita Federal juntamente com o IBGE como fonte essencial para análise estrutural do mercado de trabalho brasileiro e é por meio desta que os estabelecimentos fornecem informações referentes a cada um de seus empregados. Através da relação é possível investigar o número de trabalhadores, suas remunerações médias, e número de empresas em cada uma das atividades da cadeia da indústria criativa, a fim determinar quais municípios do estado de Minas Gerais podem ser considerados territórios criativos.

As atividades da cadeia da indústria criativa são definidas pela Firjan (2012) segundo três grandes áreas (Quadro 1). A primeira área, denominada de Núcleo Criativo, é o centro da cadeia produtiva, formado por atividades econômicas que representam o insumo principal no processo de geração de valor, nele incluem-se os segmentos de Expressões Culturais, Artes Cênicas, Artes Visuais, Música, Filme \& Vídeo, TV \& Rádio, Mercado Editorial, Software \& Computação, Arquitetura, Design, Moda e Publicidade além de Pesquisa \& Desenvolvimento e Biotecnologia. 0 Núcleo compreende 42 classes da CNAE.

As Atividades Relacionadas, que provêm diretamente bens e serviços ao núcleo, são representadas por indústrias e empresas de serviços fornecedoras de materiais e elementos fundamentais para o funcionamento do Núcleo e compreendem 68 classes da CNAE, e as atividades de Apoio são os ofertantes de bens e serviços de forma indireta ao Núcleo e compreendem 47 classes.

\section{ANÁLISE DOS RESULTADOS}

A cadeia da Indústria Criativa do Estado de Minas Gerais é responsável pela existência de 863.969 empregos (Tabela 1). Dentre as três grandes áreas da cadeia, as responsáveis pela maior 
empregabilidade são as Atividades Relacionadas (47,17\%) e o Apoio (43,45\%), compreendendo 782.944 empregos do total, já os empregos do Núcleo, representam 9,37\%, isto é, 81.025 empregados nos setores cadeia.

Tabela 1: Total de empregados, renda média ( $R \$)$ e estabelecimentos Minas Gerais - 2012

\begin{tabular}{|c|c|c|c|c|c|c|}
\hline & \multicolumn{2}{|c|}{ Empregados } & \multicolumn{2}{c|}{ Renda Média } & \multicolumn{2}{c|}{ Estabelecimentos } \\
\hline Áreas & Total & $\%$ & Total & $\%$ & Total & $\%$ \\
\hline Núcleo & 81025 & 9,38 & 207978,50 & 15,6 & 7600 & 7,2 \\
\hline Relacionadas & 407545 & 47,17 & 517988,67 & 38,82 & 64018 & 60,61 \\
\hline Apoio & 375399 & 43,45 & 608149,67 & 45,58 & 33997 & 32,19 \\
\hline Total & 863969 & 100 & 1334116,85 & 100 & 105615 & 100 \\
\hline
\end{tabular}

Nas Atividades Relacionadas (60,61\%) e de Apoio (32,18\%) predominam a maior quantidade de estabelecimentos, compreendendo $92,80 \%$ do total, sendo apenas $7,197 \%$ as empresas que representam o Núcleo criativo no estado. 


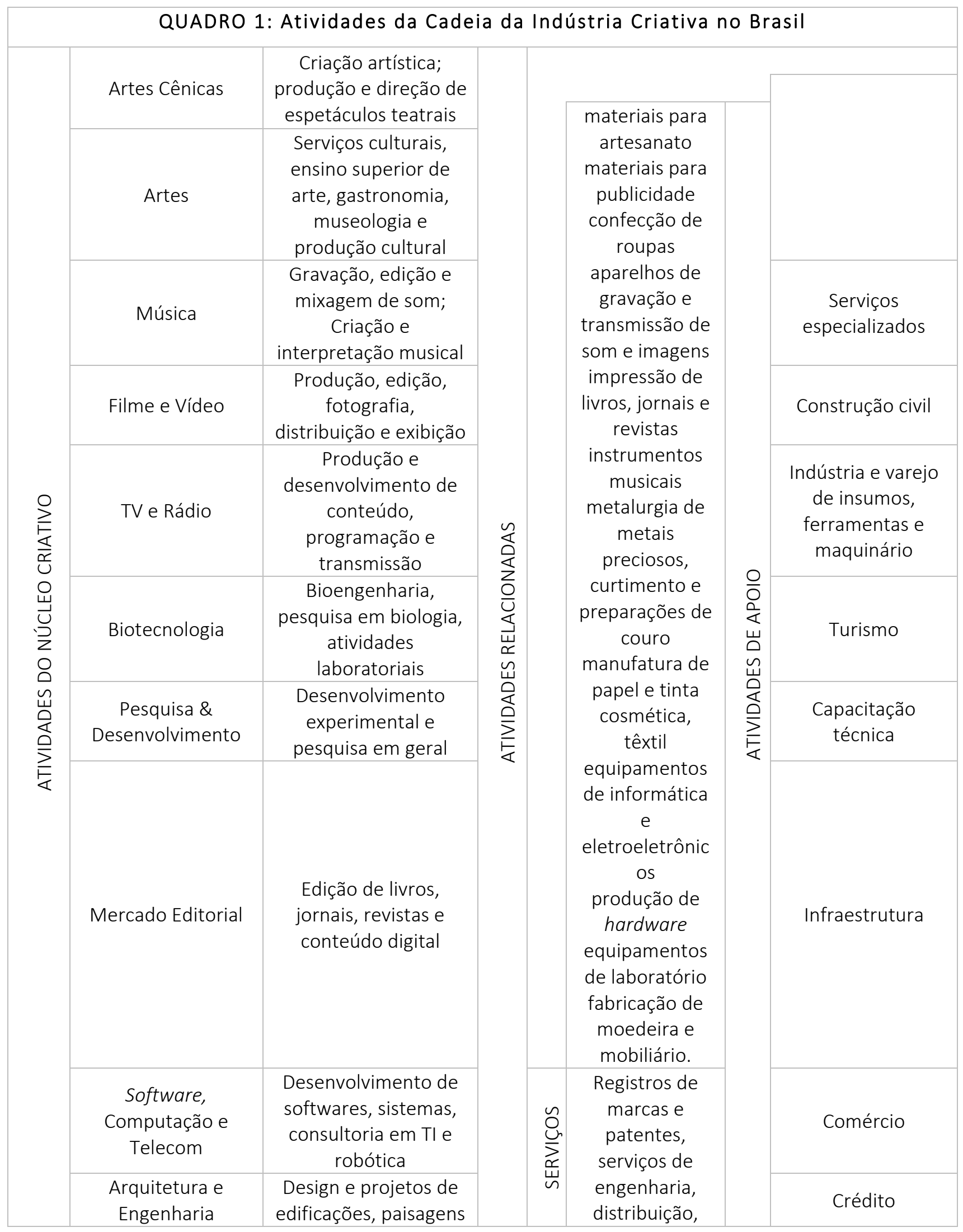

Revista de Direito da Cidade, vol. 08, no 4. ISSN 2317-7721 pp. 1778 - 17981789 


\begin{tabular}{|c|c|c|c|}
\hline & $\begin{array}{l}\text { e ambientes, } \\
\text { planejamento e } \\
\text { conservação }\end{array}$ & \multirow{5}{*}{$\begin{array}{c}\text { venda e aluguel } \\
\text { de mídias } \\
\text { audivisuais } \\
\text { comercio } \\
\text { varejista de } \\
\text { moda e } \\
\text { cosmética } \\
\text { livrarias, } \\
\text { editoras e } \\
\text { bancas de } \\
\text { jornal } \\
\text { suporte técnico } \\
\text { de hardware e } \\
\text { software } \\
\text { restauração de } \\
\text { obras de arte } \\
\text { agências de } \\
\text { notícia } \\
\text { comercio de } \\
\text { obras de arte e } \\
\text { antiguidades }\end{array}$} & \multirow[b]{2}{*}{ Serviços urbanos } \\
\hline Design & $\begin{array}{l}\text { Design gráfico, } \\
\text { multimídia e de } \\
\text { móveis }\end{array}$ & & \\
\hline Moda & $\begin{array}{c}\text { Desenho de roupas, } \\
\text { calçados e acessórios; } \\
\text { modelistas }\end{array}$ & & Outros \\
\hline $\begin{array}{c}\text { Expressões } \\
\text { Culturais }\end{array}$ & $\begin{array}{c}\text { Criação de artesanato, } \\
\text { museus biblioteca e } \\
\text { folclore }\end{array}$ & & \\
\hline Publicidade & $\begin{array}{l}\text { Atividades de } \\
\text { publicidade, } \\
\text { marketing, pesquisa } \\
\text { de mercado e } \\
\text { organizações de } \\
\text { eventos }\end{array}$ & & \\
\hline
\end{tabular}

Fonte: Firjan, 2012.

Quando se analisa a renda média, observa-se que cerca 45,58\% do total da renda média da cadeia é gerado pelas Atividades de Apoio, seguidas pelas atividades Relacionadas e do Núcleo, com $38,82 \%$ e $15,58 \%$, respectivamente.

A partir dos dados referentes ao tamanho dos estabelecimentos (Tabela 2), verifica-se que 91,92\% das empresas do Núcleo da cadeia da indústria criativa são de pequeno porte, isso significa que de um total de 7.594 estabelecimentos cadastrados nessa área, 6.981 possuem entre 0 e 19 empregados. Já as empresas de grande porte, com mais de 250 empregados representam apenas 0,487\% do total de empresas da cadeia criativa no estado. Para a área das Atividades Relacionadas, de um total de 64.018 estabelecimentos, 94,47\% possuem de 0 a 19 empregados, apenas 0,15\% possuem mais de 250 empregados, já para o Apoio, 90,9\% (30.912) são de pequeno porte, e 0,51\% de estabelecimentos possuem mais de 250 empregados e são de grande porte. Em todas as áreas da cadeia, a maioria dos estabelecimentos possui de 1 a 4 empregados, o que reforça a predominância dos estabelecimentos de pequeno porte. 
Tabela 2: Tamanho dos estabelecimentos, por número de empregados -

Minas Gerais - 2012

\begin{tabular}{|c|c|c|c|c|c|c|}
\hline \multirow{2}{*}{ Empregados } & \multicolumn{2}{|c|}{ Nucleo } & \multicolumn{2}{c|}{ Relacionadas } & \multicolumn{2}{c|}{ Apoio } \\
\hline & Total & $\%$ & Total & $\%$ & Total & $\%$ \\
\hline 0 & 1046 & 13,77 & 8786 & 13,72 & 9148 & 26,90 \\
\hline 1 a 4 & 4096 & 53,93 & 37842 & 59,11 & 13778 & 40,52 \\
\hline 5 a 9 & 1139 & 14,99 & 9241 & 14,43 & 4967 & 14,61 \\
\hline 10 a 19 & 700 & 9,217 & 4613 & 7,20 & 3019 & 8,88 \\
\hline 20 a 49 & 424 & 5,58 & 2474 & 3,86 & 1905 & 5,60 \\
\hline 50 a 99 & 100 & 1,316 & 672 & 1,05 & 633 & 1,86 \\
\hline 100 a 249 & 52 & 0,68 & 292 & 0,456 & 370 & 1,08 \\
\hline 250 a 499 & 24 & 0,316 & 66 & 0,10 & 106 & 0,31 \\
\hline 500 a 999 & 12 & 0,158 & 21 & 0,033 & 49 & 0,14 \\
\hline 1000 ou mais & 1 & 0,013 & 11 & 0,017 & 22 & 0,06 \\
\hline Total & 7594 & 100 & 64018 & 100 & 33997 & 100 \\
\hline Fonte: Elaboração própria com base nos dados da RAIS (2012).
\end{tabular}

Em relação ao grau de instrução dos empregados da cadeia da indústria criativa (Tabela 3), em todas as áreas predominam trabalhadores com o ensino médio completo, compreendendo 51,44\% dos empregados das áreas das Atividades Relacionadas, 46,2\% dos empregados do Núcleo e $32,7 \%$ dos empregados do Apoio. Os níveis Fundamental Completo e Médio compreendem mais de $60 \%$ do nível de escolaridade em todas as áreas da cadeia, o que reforça a importância da educação na geração de empregos no estado.

Tabela 3: Grau de instrução dos empregados do Núcleo, Atividades e do Apoio Minas Gerais - 2012

\begin{tabular}{|c|c|c|c|c|c|c|}
\hline \multirow{2}{*}{ Nível de Escolaridade } & \multicolumn{2}{|c|}{ Núcleo } & Atividades Relacionadas & \multicolumn{2}{c|}{ Apoio } \\
\cline { 2 - 7 } & Total & $\%$ & Total & $\%$ & Total & $\%$ \\
\hline Analfabeto e até 5 ${ }^{\circ}$ incompleto & 2.513 & 3,1 & 11.082 & 2,72 & 35.330 & 9,4 \\
\hline $5^{\circ}$ Completo $^{*}$ & 8.494 & 10,5 & 57.216 & 14,04 & 96.026 & 25,6 \\
\hline Fundamental Completo & 11.583 & 14,3 & 110.798 & 27,2 & 104.926 & 27,95 \\
\hline Médio & 37.427 & 46,2 & 209.658 & 51,44 & 122.793 & 32,7 \\
\hline Superior & 21.008 & 25,9 & 18.791 & 4,6 & 16.324 & 4,35 \\
\hline Total & 81.025 & 100 & 407.545 & 100 & 375.399 & 100 \\
\hline
\end{tabular}

Fonte: Elaboração própria com base nos dados da RAIS (2012). 


\section{Participações Municipais}

Nesta secção será exibida, em mapas, a distribuição espacial municipal da renda e do emprego das classes criativas nos municípios do estado de Minas Gerais. Dentre os 853 municípios de Minas Gerais, destaca-se os primeiros 5 que apresentam uma maior participação de empregos criativos em cada área.

$\mathrm{Na}$ área do Núcleo (Mapa 1), os 5 municípios que possuem maior participação de empregos da cadeia criativa são Urucânia, São João da Barra, Nova Lima, Rio Acima e Brumadinho, verificando uma participação acima de 0,05\% em todos estes.

O munícipio que apresenta a maior participação de empregos criativos em relação ao total é Urucânia, com 34\% de empregos. Este possui um total de 4.124 postos de trabalho, sendo 1.429 na economia criativa, com 1.427 empregos na área de construção de obras de arte especiais. Área esta que também é responsável pelos 158 empregos criativos em São José da Barra que possui uma participação de 13\% no total de 1.151 empregos do município.

O município de Nova Lima localiza-se na região metropolitana de Belo Horizonte. Este possui um total de empregos de 47.213 e deste 5.846 são de áreas da economia criativa, porém, apesar de um volume maior de empregos, a proporção de empregos criativos é menor do que nos municípios de Urucânia e São José da Barra, além de estes empregos compreender diversas classes dentro da área do Núcleo criativo, podendo destacar as Atividades técnicas relacionadas à arquitetura e engenharia, consultoria em tecnologia da informação e também a construção de obras de arte especiais. 


\section{Mapa 1: Participação do Emprego do Núcleo no Emprego Total - Minas Gerais - 2012}

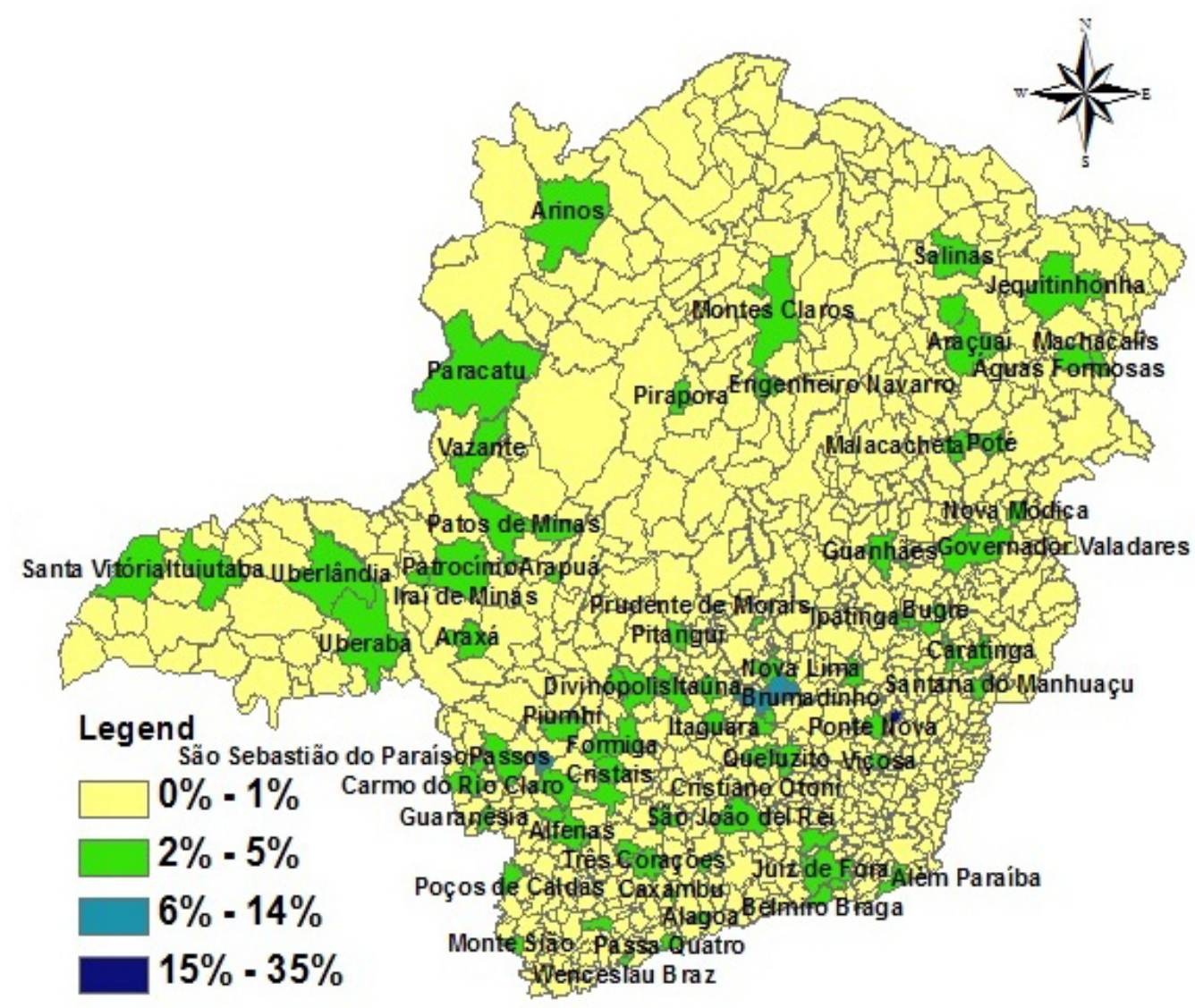

Fonte: Elaboração própria com base nos dados da RAIS (2012).

O município de Rio Acima se destaca com 152 empregos criativos, sendo 132 na classe de consultoria em tecnologia da informação, com uma participação de 9,7\% de um total de 1.566 empregos. O quinto município com maior participação em empregos criativos em relação ao total (8.277) é Brumadinho, com aproximadamente 7\% (574) de empregos da cadeia, tendo como principal área de empregabilidade a de Artes cênicas, espetáculos e atividades complementares. Destaca-se na cidade o maior museu de arte contemporânea que leva o nome de Inhotim que é considerado uma possibilidade de desenvolvimento da economia criativa do município.

Destes resultados pode-se destacar a proximidade dos municípios e suas semelhanças em relação às classes criativas de emprego. Um exemplo são os municípios de Nova Lima e Rio Acima, 
distantes um do outro em apenas $16 \mathrm{~km}$ e se destacam pela mesma classe criativa (consultoria em tecnologia da informação) o que pode ser um fator de tendência e ou referência para o desenvolvimento das cidades. Urucânia e São José da Barra possuem a mesma classe criativa de empregabilidade, mas suas localidades no Estado são de cerca de $550 \mathrm{~km}$ distantes, logo as características de cada município podem ser outro fator de desenvolvimento das atividades criativas.

Para a área das Atividades Relacionadas (Mapa 2), os 5 principais municípios em termos de participação nos empregos criativos, são: Dores de Campos, Rodeiro, Nova Serrana, Mar de Espanha e Perdigão, todos com participações acima de 6\%.

\section{Mapa 2: Participação do Emprego das Atividades Relacionadas no Emprego Total - Minas Gerais - 2012}

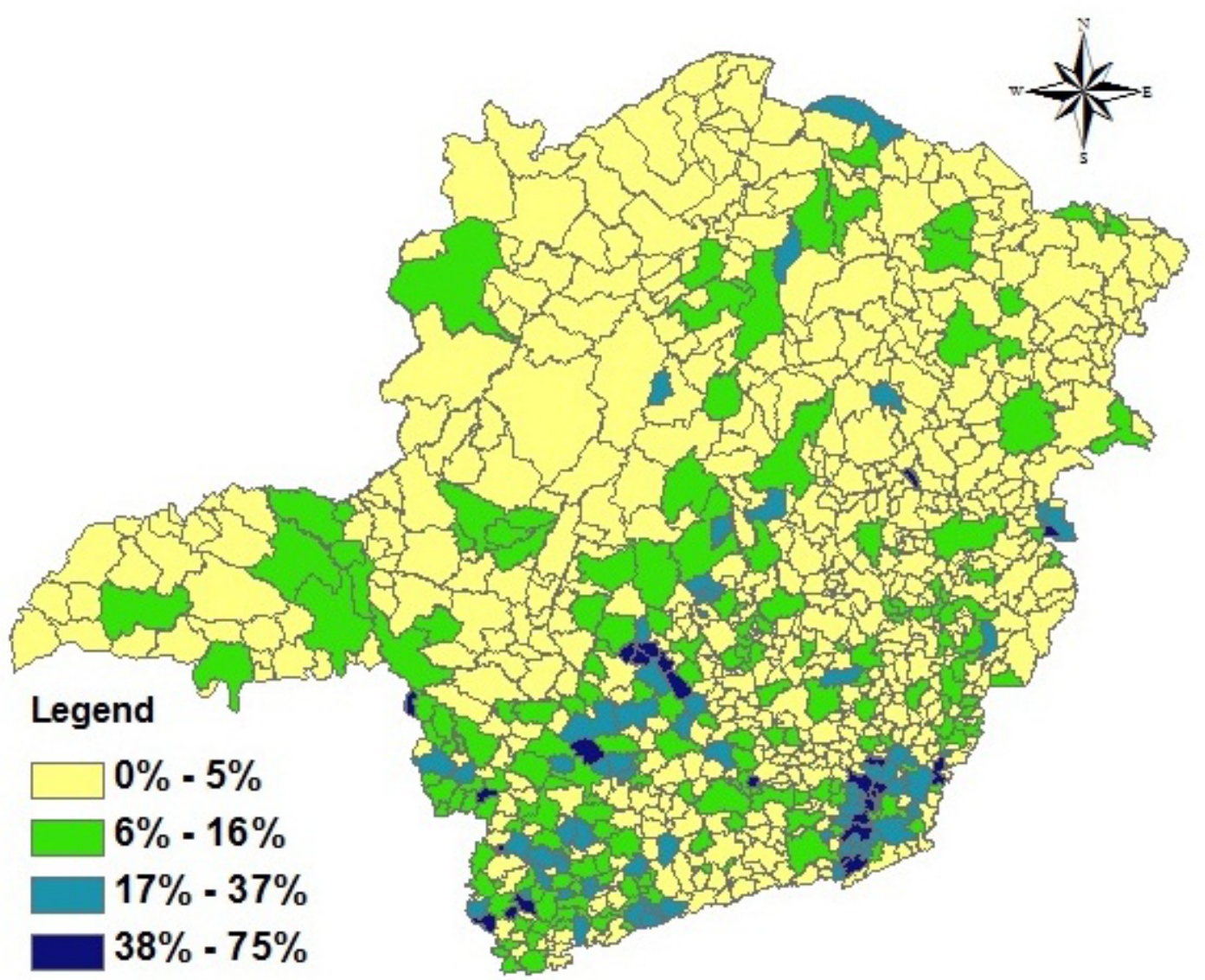

Fonte: Elaboração própria com base nos dados da RAIS (2012). 
Em Dores de Campos, onde se verifica uma participação de 74,8\%, do emprego da cadeia criativa, as classes que mais se destacam são Fabricação de artefatos de couro e Fabricação de calçados de couro, com 2.081 empregos de um total de 2.315 empregos. Esta concentração decorre da história da cidade que se desenvolveu centrada na criação de gado face às boas pastagens e, no desenvolvimento da indústria de couro centrada na fabricação e venda de arreios.

Com $71,6 \%$ de empregos criativos, no município de Rodeiro prevalecem empregos da classe de Fabricação de móveis com predominância de metal, responsável por 1.831 empregos criativos de um total de 2.281. O município de Nova Serrana aparece com 65,6\% de empregos criativos, referente a 17.156 empregos de um total de 26.129. dos empregos criativos destacam as classes de Fabricação de Calcados com 15.441 empregos divididos em Fabricação de tênis de qualquer material, fabricação de calçados de material sintético, fabricação de calçados de materiais não especificados anteriormente e fabricação de partes para calçados. Mar de Espanha possui 1.878 empregos criativos, de um total de 3.017 empregos, sendo 1.844 das classes de Confecção de roupas íntimas e Confecção de Roupas de vestuário, que corresponde a 62,2\% dos empregos do município.

Responsável por 1.282 empregos criativos gerando uma participação de 59,6\% o município de Perdigão é o quinto município de Minas Gerais em que se destacam as atividades criativas, sendo as classes empregatícias de destaque as de Fabricação de calçados de couro, de tênis de qualquer material, de calçados de material sintético e de parte de calçados. A fabricação de calçados movimenta a economia do município sendo considerado o segundo polo calçadista da região. O município de Perdigão se assemelha ao município de Nova Serrana na predominância de Fabricação de calçados, sendo localizado a menos de 400 km de distância um do outro.

$\mathrm{Na}$ área de Apoio da cadeia da Indústria Criativa (Mapa 3), os 5 municípios que se destacam nas participações dos empregos criativos são ljaci, Córrego Fundo, Virginópolis, Araçai, Igaratinga, que apresentam mais de 38\% de participações dos empregos criativos.

ljaci, município que apresenta a maior participação de empregos criativos em relação ao total de empregos, 49,1\%, tem como principais atividades a Fabricação de cimento, construção de edifícios e Serviços especializados para construção, responsáveis pela geração de 733 empregos criativos, de um total de 777. Córrego Fundo possui 1.581 empregos, sendo 705 o total de 
empregos criativos que geram uma participação de $47,6 \%$ tendo como destaque a atividade de Fabricação de cal e gesso que é responsável por 692 empregos no setor.

Virginópolis, responsável por 628 empregos criativos que equivalem a uma participação de 45,3\% de um total de 1.385 empregos, concentrados na mesma classe empregatícia, sendo ela a de Obras para geração e distribuição de energia elétrica e para telecomunicações. Araçaí, com participação de 39,5\% destaca-se na atividade de Tecelagem de fios de algodão que é responsável por 217 empregos criativos, de um total de 2019. Com participação de 38,8\% e responsável por 1.165 empregos criativos o município de Igaratinga destaca-se na atividade de Fabricação de produtos cerâmicos não-refratários para uso estrutural na construção empregando um total de 892 trabalhadores.

\section{Mapa 3: Participação o Emprego do Apoio no Emprego Total - Minas Gerais} 2012

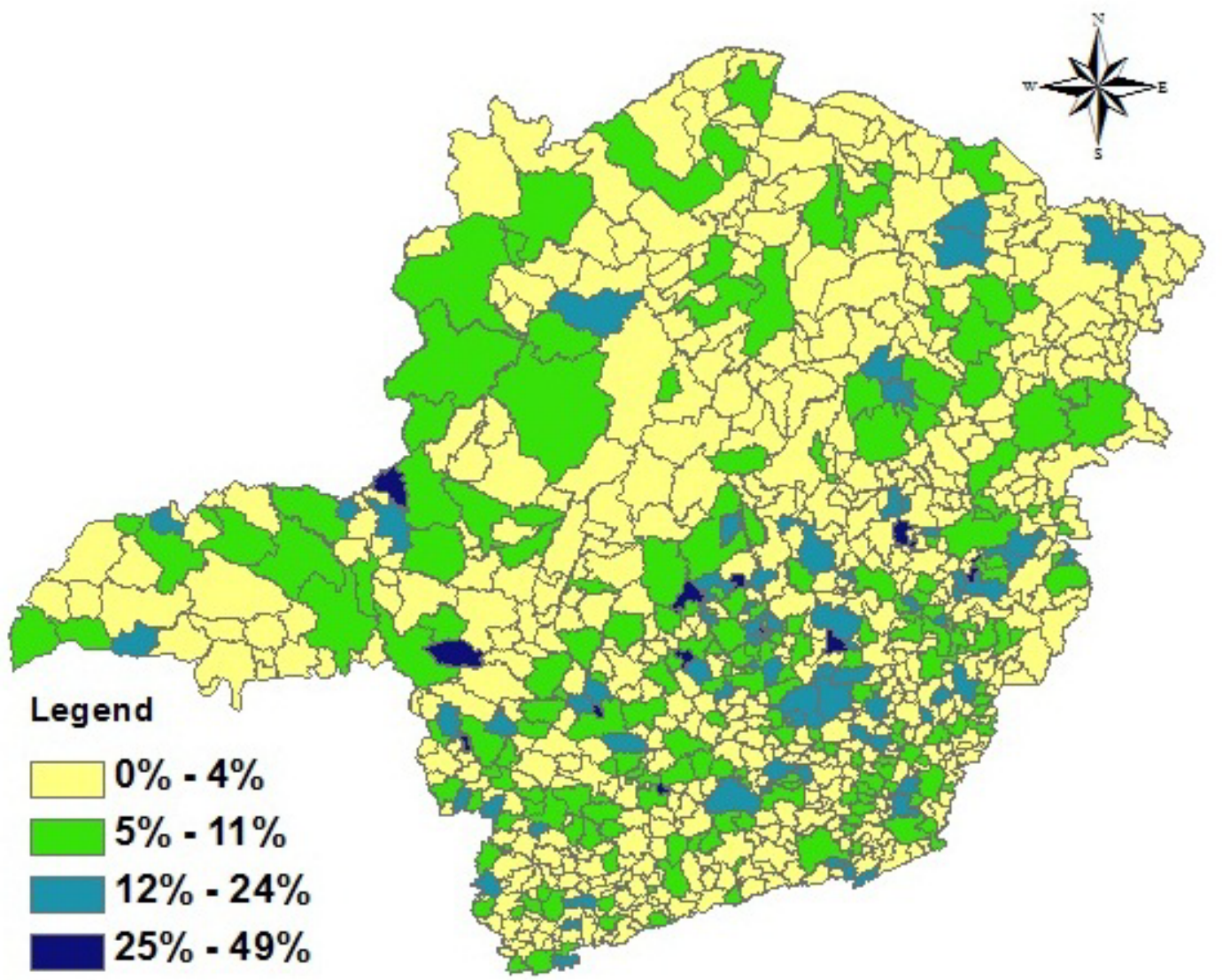

Fonte: Elaboração própria com base nos dados da RAIS (2012).

Revista de Direito da Cidade, vol. 08, no 4. ISSN 2317-7721 pp. 1778 - $1798 \quad 1796$ 


\section{CONSIDERAÇÕES FINAIS}

O desenvolvimento de um país ou de uma região está cada dia mais dependente de inovações, tanto de tecnologias quanto de recursos renováveis e de ideias, porém esta última quando interligada à criatividade, a imaginação e a inovação abrem novas possibilidades de crescimento e desenvolvimento. Assim, o trabalho busca analisar a participação da economia criativa nos municípios do Estado de Minas Gerais utilizando dados da RAIS no ano de 2012.

Os resultados revelam que o estado de Minas Gerais possui 863.969 empregos criativos espalhados por 105.615 estabelecimentos, a grande maioria de pequeno porte, que geram uma renda de $\mathrm{R} \$ 1$ 1.192.543.535,01. A maioria da força de trabalho criativa possui graus de instrução até o Ensino Fundamental e Ensino Médio Completo. Dos 853 municípios que compõem o estado, os que se destacam possuindo atividades da cadeia criativa se localizam principalmente nas Regiões Metropolitana, Zona da Mata, Campo das Vertentes e Sul de Minas, estando as atividades principalmente concentradas na região da capital.

\section{REFERÊNCIAS}

BARRETO, L. Economia criativa: Potencial a explorar. In: REIS, A. C. F.; KAGEYMA, P. (Orgs). Cidades Criativas - Perspectivas. Câmara Brasileira do Livro, São Paulo: Garimpo de Soluções, Brasil. 2011, 176p.

BRASIL. Ministério da Cultura. Plano da Secretaria de Economia Criativa: Políticas, Diretrizes e Ações 2011-2014. Brasília, 2011. 79p.

CAIADO, A. S. C. (Coord). Economia Criativa na Cidade de São Paulo: Diagnóstico e Potencialidade. São Paulo: Fundap 2011, 174p.Disponível emhttp://novo.fundap.sp.gov.br/arquivos/PDF/Livro_Economia_Criativa_NOVO.pdf. Acesso em: 22 de outubro de 2013.

CARVALHO, C. L. Cidades criativas e a transformação. In: REIS, A. C. F.;

DUISENBERG, E. S. Economia Criativa: uma opção de desenvolvimento viável? In: REIS, Ana Carla Fonseca (Org.). Economia Criativa como estratégia de desenvolvimento: uma visão dos países em desenvolvimento. São Paulo: Itaú Cultural, 2008.

FIRJAN. Federação das indústrias do estado do Rio de Janeiro. Indústria Criativa: Mapeamento da Indústria Criativa no Brasil, 2012. Disponível em: http://www.firjan.org.br. Acesso em: 04 de novembro de 2013.

Revista de Direito da Cidade, vol. 08, № 4. ISSN 2317-7721 pp. 1778 - $1798 \quad 1797$ 
A cadeia da indústria criativa no Brasil, 2008. Disponível em: http://www.firjan.org.br. Acesso em: 20 de outubro de 2013.

MEDEIRO JUNIOR, H.; GRAND JUNIOR, J.; FIGUEIREDO, J. L. A importância no desenvolvimento econômico da cidade do Rio de Janeiro. Rio de Janeiro: Secretaria Extraordinária de Desenvolvimento, 2011.

REIS, A. C. F. Cidades Criativas, Turismo Cultural e Região Urbana. [S. I.: s. n.], [2009? ] Disponível em: http://www.redbcm.com.br/arquivos/cidadescriativas/ana-carla-fonseca-cidades-criativas.pdf. Acesso em: 18 de outubro de 2013.

REIS, A. C. F.; KAGEYMA, P. (Orgs). Cidades Criativas - Perspectivas. Câmara Brasileira do Livro, São Paulo: Garimpo de Soluções, Brasil. 2011, 176p.

REIS, A. C. F. (Org). Economia Criativa como estratégia de desenvolvimento: uma visão dos países em desenvolvimento. São Paulo: Itaú Cultural, 2008. Disponível em: http://novo.itaucultural.org.br. Acesso em: 19 de outubro de 2013.

PARDO, J. Cidade Criativa. In: REIS, A. C. F.; KAGEYMA, P. (Orgs). Cidades Criativas - Perspectivas. Câmara Brasileira do Livro, São Paulo: Garimpo de Soluções, Brasil. 2011, 176p.

PINTO, G; ARAÚJO, M. F. A. O Mapeamento das Indústrias criativas no Brasil. Revista de Design, Inovação e Gestão Estratégica - REDIGE. SENAI. Rio de Janeiro, RJ, 2013. Disponível em: www.cetiqt.senai.br/redige. Acesso em: 15 de dezembro de 2013.

(SEBRAE), Serviço Brasileiro de Apoio a Micro e Pequenas Empresas. Termo de Referência Atuação do Sistema SEBRAE na Economia Criativa. Brasília, DF, 2012. Disponível em: //www.sebrae.com.br/serviços.

STRICKLAND, B. Cidade Criativa. In: REIS, A. C. F.; KAGEYMA, P. (Orgs). Cidades Criativas Perspectivas. Câmara Brasileira do Livro, São Paulo: Garimpo de Soluções, Brasil. 2011, 176p.

Trabalho enviado em 03 de abril de 2016.

Aceito em 17 de julho de 2016. 